\title{
Conjugated and free sterols from black bean (Phaseolus vulgaris L.) seed coats as cholesterol micelle disruptors and their effect on lipid metabolism and cholesterol transport in rat primary hepatocytes
}

\author{
Rocio A. Chávez-Santoscoy $\cdot$ Armando R. Tovar • \\ Sergio O. Serna-Saldivar • Nimbe Torres • \\ Janet A. Gutiérrez-Uribe
}

Received: 20 August 2013/Accepted: 8 November 2013/Published online: 1 December 2013

(C) Springer-Verlag Berlin Heidelberg 2013

\begin{abstract}
Phytosterols have been widely studied for their cholesterol-lowering effect. Conjugated phytosterol forms have been found more active than free moieties. There are no reports about the sterol profile of black bean seed coats neither its effects on cholesterol metabolism. The aim of this research was to identify and quantify phytosterols from black bean seed coats and to determine their effects on cholesterol micellar solubility and on mRNA and key protein levels involved in lipid/cholesterol metabolism and cholesterol transport in primary rat hepatocytes. Free phytosterols, acylated steryl glycosides, and steryl glycosides were extracted from black bean seed coats. They were identified through HPLC-MS-TOF and quantified through HPLC equipped with UV-visible and evaporative light-scattering detectors. Free and conjugated phytosterols from the coats significantly increased the inhibitory effect of cholesterol micelle formation compared with stigmasterol, which was used as control $(P<0.05)$. In addition, phytosterols of black bean seed coat decreased lipogenesis by the downregulation of lipogenic proteins such as sterol regulatory element-binding protein 1 and fatty acid synthesis (FAS) in primary rat hepatocytes. Regarding $\beta$-oxidation, phytosterols upregulated the expression of carnitine
\end{abstract}

R. A. Chávez-Santoscoy · S. O. Serna-Saldivar .

J. A. Gutiérrez-Uribe $(\bowtie)$

Departamento de Biotecnología e Ingeniería de Alimentos, Centro de Biotecnología FEMSA, Tecnológico de Monterrey-

Campus Monterrey, Av. Eugenio Garza Sada 2501 Sur,

C.P. 64849 Monterrey, NL, Mexico

e-mail: jagu@itesm.mx

\section{A. R. Tovar · N. Torres}

Departamento de Fisiología de la Nutrición, Instituto Nacional de Ciencias Médicas y Nutrición Salvador Zubirán, Vasco de Quiroga No. 15, C.P. 14000 Mexico, DF, Mexico palmitoyltransferase I and promoted the $\beta$-oxidation of long-chain fatty acids. Phytosterols inhibited cholesterol micellar solubility and reduced the activation of the liver X receptor, decreasing hepatic FAS and promoting hepatic $\beta$-oxidation of long-chain fatty acids.

Keywords Black bean - Cholesterol lowering · Phytosterol composition · Lipid metabolism .

Lipogenesis · $\beta$-Oxidation

$\begin{array}{ll}\text { Abbreviations } \\ \text { ABCG } & \text { ATP-binding cassette subfamily G members } \\ \text { ASG } & \text { Acylated steryl glycosides } \\ \text { CPT1 } & \text { Carnitine palmitoyltransferase I } \\ \text { ELSD } & \text { Evaporative light-scattering detector } \\ \text { FAS } & \text { Fatty acid synthesis } \\ \text { HMGCR } & \text { 3-Hydroxy-3-methylglutaryl-CoA reductase } \\ \text { LXR } & \text { Liver X receptor } \\ \text { Ph } & \text { Phytosterols from black bean seed coat } \\ \text { SG } & \text { Steryl glycosides } \\ \text { SREBP } & \text { Sterol regulatory element-binding protein } \\ \text { T } & \text { T0901317 }\end{array}$

\section{Introduction}

Phytosterols are structurally similar to cholesterol and act in the intestine lumen to lower cholesterol absorption via the higher excretion of fecal cholesterol (Ostlund 2004). The Food and Drug Administration (FDA) (2010) has considered these plant sterols as generally recognized as safe (GRAS) and established that the dietary intake necessary to achieve significant cholesterol plasma reductions 
$(5-15 \%)$ is 2 g per day. Similarly, the National Cholesterol Education Program (NCEP) (2001) recommends for adults the daily intake of $2 \mathrm{~g}$ phytosterols to reduce plasma LDL and the risk of cardiovascular diseases. However, a conventional Western diet provides only an average of $250 \mathrm{mg} /$ day of phytosterols.

Studies with the free forms of phytosterols related to their cholesterol-lowering effects have only been addressed toward the reduction in cholesterol absorption (Carr 2002; Guderian et al. 2007; Lee et al. 2012; Rasmussen et al. 2006; Trautwein and Duchateau 2003). One of the proposed mechanisms for the interference of cholesterol intestinal absorption is the inhibition of micellar solubility (Jesch and Carr 2006; Trautwein and Duchateau 2003). Remarkably, esterified phytosterols have been found more active in the cholesterol-lowering effect than free counterparts (Guderian et al. 2007; Rasmussen et al. 2006). Glycoside sterols (GS) and acylated steryl glycosides (ASG) are the major forms of phytosterols in many foods (Ostlund 2002), and according to Lin et al. (2009), these chemical forms have a similar reduction effect of cholesterol absorption compared with sterol esters. Further studies have demonstrated that the bioactive components responsible for reducing cholesterol absorption are ASG and SG, but not the free phytosterols (Lin et al. 2011). Lin et al. (2011) reported that ASG and SG present in the lumen and mucosa of mice reduced cholesterol absorption, and despite their low absorption, they significantly reduced both plasma and hepatic cholesterol. Other reports showed that ASG have also been used to enhance drug delivery because they are well recognized by some hepatic receptors, allowing the administrated drug to accumulate up to $80 \%$ in the liver (Maitani et al. 2005). Despite the limited absorption of ASG, there is not knowledge whether small amounts of these compounds may exert biological effects in liver cells.

There is limited information about the effect of specific free phytosterols (sitosterol and stigmasterol) on the expression of key genes of cholesterol metabolism. A significant decrease in the relative expression of hepatic sterol regulatory element-binding protein 2 (SREBP-2), 3-hydroxy-3-methylglutaryl-CoA reductase (HMGCR), and intestinal ATP-binding cassette subfamily G 5 (ABCG5) has been observed in hamsters fed with a highcholesterol diet and pure sitosterol or stigmasterol (Liang et al. 2011). SREBP is a family of transcription factors that regulate lipid metabolism and activate the expression of more than 30 genes dedicated to the synthesis and uptake of cholesterol, as well as fatty acid synthesis (Horton 2002; Sato 2010). On the other hand, ABCG5 and 8 are transporters that belong to the family of reverse cholesterol transport and are also responsible to limit intestinal absorption and promote biliary excretion of hepatic sterols (Graf et al. 2002).

Beans are an important source of several phytosterols, but these phytochemicals have been quantified after the hydrolysis of the seed (Iriti et al. 2009; Nyström et al. 2012; Ryan et al. 2007). For instance, the most abundant phytosterol in kidney beans is sitosterol, containing $86.5 \mathrm{mg} / 100 \mathrm{~g}$ (Ryan et al. 2007). In addition, other authors reported that sitosterol is the main phytosterol found in common beans with a concentration of $27.2 \mathrm{mg} /$ $100 \mathrm{~g}$ (Iriti et al. 2009). For black beans, the most abundant reported phytosterol is also sitosterol, and the proportion of acylated steryl glycosides is greater than that of steryl glycoside sterols (Nyström et al. 2012). To our knowledge, it has not been reported the sterol profile of black bean (Phaseolus vulgaris L.) seed coats nor their effects on cholesterol metabolism. It is important to point out that black bean is one of the most frequent legume seeds consumed in the Mexican diet and is extensively used to prepare an array of foods of the Mexican cuisine. However, the consumption of beans has decreased during the past decades, and interestingly during this time span, there has been an increase in the incidence of hypercholesterolemia and cardiovascular diseases (Díaz-Batalla et al. 2006). Thus, black bean consumption could benefit individuals from high serum cholesterol concentration and thus reduction in the risk of cardiovascular diseases.

Thus, the aim of this study was to identify and quantify phytosterols, in their free and conjugated forms, in black bean (Phaseolus vulgaris L.) seed coats, and to determine their effects in cholesterol micellar solubility and in key protein levels and gene expression involved in lipid/cholesterol metabolism and cholesterol transport in primary rat hepatocytes.

\section{Materials and methods}

\section{Seed coat samples}

Phaseolus vulgaris L. var. San Luis was obtained from Sinaloa, Mexico, during the month of March of 2011. The seeds were stored at $4{ }^{\circ} \mathrm{C}$ and relative humidity of $85 \%$. Black beans were wiped with a flannel and then tempered in a plastic bag with distilled water in a 100:1 (w/v) ratio at room temperature for $24 \mathrm{~h}$. The conditioned black beans were placed on trays for drying at $60{ }^{\circ} \mathrm{C}$ for $6 \mathrm{~h}$ in an oven (Electrolux, EOB31003X, Spain). Later, the seed coats were removed using a mechanical seed decorticator (Square D, SC-DGE 4364, India) for $90 \mathrm{~s}$. The mixture of decorticated beans was separated by three sieves into cotyledons $(2.81 \mathrm{~mm})$; seed coats $(1.00 \mathrm{~mm})$; a mixture of 
fine particles of cotyledons, hilum, and seed coats $(0.251 \mathrm{~mm})$; and a bottom pan that collected the finest particles. Subsequently, the seed coats were milled with a coffee grinder (Krups GX4100, Mexico).

Extraction of sterols associated with black bean seed coats

Dihydrocholesterol ( $5 \alpha$-cholestan-3 $\beta$-ol, Sigma, St. Louis, MO, USA) was used as internal standard. The extractions were performed with hexane using a mass-solvent ratio of 1:10 w/v. The mixture was stirred for $3 \mathrm{~h}$ at $250 \mathrm{rpm}$ at a temperature of $35{ }^{\circ} \mathrm{C}$ and left for one additional hour. The supernatant was recovered and vacuum filtered through a Whatman filter paper No. 1. The resulting extract was concentrated in a rotary evaporator to remove the organic solvent. The bath temperature was set at $40{ }^{\circ} \mathrm{C}$, and pressure in the vacuum pump at a range of -70 to $-90 \mathrm{kPa}$. Once hexane was removed, the extract rich in phytosterols was lyophilized and the resulting powder stored at $-80{ }^{\circ} \mathrm{C}$ until analyses.

\section{Hydrolysis of extract rich in phytosterols}

Two grams of lyophilized extract was hydrolyzed with $10 \mathrm{~mL}$ of $6 \mathrm{M} \mathrm{HCl}$ for $60 \mathrm{~min}$ at $70{ }^{\circ} \mathrm{C}$; every $10 \mathrm{~min}$ the samples were manually shaken. After cooling the samples for $20 \mathrm{~min}$ at room temperature, lipids were extracted twice with $7 \mathrm{~mL}$ of hexane/diethylether 1:1 (v:v). The organic layer was recovered and evaporated to dryness. Then for saponification, the dried organic layer was dissolved in $4 \mathrm{~mL}$ of ethanol, and $5 \mathrm{~mL}$ of $\mathrm{KOH}$ was added. The mixture was shaken in a vortex and hydrolyzed for $30 \mathrm{~min}$ at $70^{\circ} \mathrm{C}$. After that, the mixture was cooled at room temperature, and $4 \mathrm{~mL}$ of distilled water and $7 \mathrm{~mL}$ of hexane were added. The organic layer was recovered, and other $7 \mathrm{~mL}$ of hexane was added and recovered. The total organic layer was evaporated to dryness. The dried fraction was dissolved in $1 \mathrm{~mL}$ of hexane for HPLC analysis.

Sterols identification and quantification

The identification of phytosterols was performed in a HPLC-MS-TOF (Model G1969A Agilent 1100 Santa Clara, CA, USA) with the same chromatographic conditions described above for the HPLC-DAD-ELSD analysis. The free forms were confirmed by retention time of each standard in the HPLC column. For the identification of conjugated forms, ionization tests were performed to fragment the molecular ion and obtain the corresponding fragmentation pattern. Mass spectra were collected using electrospray source in positive mode $(\mathrm{ESI}+)$ under the following conditions: $\mathrm{m} / \mathrm{z}$ range, $100-1,400$; nitrogen gas; gas temperature, $250{ }^{\circ} \mathrm{C}$; drying gas flow rate, $13 \mathrm{~L} / \mathrm{min}$; nebulizer pressure, 50 psig; capillary voltage, 4,000 V; and fragment voltage, $80 \mathrm{~V}$. Extracted ion chromatograms were obtained considering accurate mass of phytosterols or their adducts, with an error range of 0.01 units using the Analyst QS 1.1 software (Applied Biosystems, Carlsbad, CA, USA).

Phytosterol quantifications were performed in HPLC equipped with UV-Visible detector and an Evaporative Light Scattering Detector, HPLC-UV-VIS-ELSD (1200 Series, Agilent Technologies, Santa Clara, CA, USA). The HPLC was equipped with a Luna C8 column $(250 \times 4.6 \mathrm{~mm}$ i.d; Phenomenex, Torrance, CA, USA); injection volume was $20 \mu \mathrm{L}$, and the mobile phase consisted of (A) acetonitrile and (B) $55 \%$ methanol and $45 \%$ water (acidified with $1 \%$ formic acid). The elution gradient for B was as follows: $0-7 \mathrm{~min}, 0 \%$ (flow rate of $0.6 \mathrm{~mL} / \mathrm{min}) ; \quad 7-15 \mathrm{~min}, \quad 0-15 \% \quad(0.6-1.2 \mathrm{~mL} / \mathrm{min})$; 15-20 $\mathrm{min}, 15-80 \%(1.2-1.5 \mathrm{~mL} / \mathrm{min})$; and $20-50 \mathrm{~min}$, $80-100 \%(1.5 \mathrm{~mL} / \mathrm{min})$. The column temperature was maintained at $40{ }^{\circ} \mathrm{C}$. ELSD was adjusted to $50{ }^{\circ} \mathrm{C}$ with a nitrogen pressure of 1.8 bar. ELSD signal was used to quantify free and conjugated forms of stigmasterol and sitosterol. Campesterol, free or conjugated, and cholesterol were measured at $205 \mathrm{~nm}$. Quantifications were performed using calibration curves of standards of stigmasterol, sitosterol, and campesterol (Sigma, St. Louis, MO, USA), and conjugated forms were quantified as equivalents of the corresponding phytosterol in its free form. In the case of $\Delta^{5}$-avenasterol forms, cholesterol was used for quantification.

Inhibition of in vitro cholesterol micellar solubility

The in vitro micellar solubility of cholesterol was measured according to the method described before (Zhong et al. 2007). Micellar solutions (7 mL) containing $10 \mathrm{mM}$ sodium taurocholate (Sigma, St. Louis, MO, USA), 2 mM cholesterol (Sigma, St. Louis, MO, USA), $5 \mathrm{mM}$ oleic acid (Sigma, St. Louis, MO, USA), $132 \mathrm{mM} \mathrm{NaCl,} 15 \mathrm{mM}$

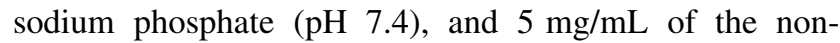
hydrolyzed phytosterols extract or $5 \mathrm{mg} / \mathrm{mL}$ of sitosterol or $3 \mathrm{mg} / \mathrm{mL}$ of sitosterol or $5 \mathrm{mg} / \mathrm{mL}$ of stigmasterol were prepared by sonication (Ultrasonic Homogenizer VP-5, Taitec Co. Ltd., Japan). The sitosterol concentration of $3 \mathrm{mg} / \mathrm{mL}$ was selected to assay the effect of the same proportion of sitosterol contained in the phytosterol extract, and $5 \mathrm{mg} / \mathrm{mL}$ of sitosterol and stigmasterol was evaluated to compare the effect of free forms of phytosterol with the effect of the non-hydrolyzed phytosterol extract. The mixture was incubated at $37{ }^{\circ} \mathrm{C}$ for $24 \mathrm{~h}$ and centrifuged at $100,000 \mathrm{~g}$ for $60 \mathrm{~min}$ at $37^{\circ} \mathrm{C}$. The supernatant portion was collected for the determination of cholesterol concentration 
using the method previously described (Chávez-Santoscoy et al. 2013). Data were expressed as inhibition of cholesterol micellar solubility $(\%)$ obtained as $[\mathrm{Cs} /(\mathrm{Ci}-$ $\mathrm{Co})] \times 100$, where $\mathrm{Cs}$ is cholesterol concentration in supernatants with the tested extracts or control, Co is cholesterol concentration in supernatant without disruptor, and $\mathrm{Ci}$ was the initial cholesterol concentration, which in this particular case was $2 \mu \mathrm{g} / \mathrm{mL}$.

\section{Culture of primary rat hepatocytes}

Wistar rat hepatocytes were isolated by collagenase perfusion and separated from non-parenchymal liver cells by centrifugation at $325 g$ as previously described (Berry and Friend 1969). Primary hepatocytes were plated in a six-well plate $\left(9.6 \mathrm{~cm}^{2} /\right.$ well) (CorningCellBIND, Tewksbury, MA). At $4 \mathrm{~h}$ after plating hepatocytes, phytosterol extracts at different dosages up to $76.1 \mu \mathrm{g} / \mathrm{L}$ and/or $10 \mu \mathrm{mol} / \mathrm{L}$ of T0901317 (Sigma, St. Louis, MO, USA) were added. The hepatocytes were stimulated for $24 \mathrm{~h}$ by each treatment. Total RNA from the hepatocytes was obtained using Trizol reagent (Life Technologies, Carlsbad, CA, USA) with the protocol recommended for the provider, quantified in a NanoDrop spectrophotometer (NanoDrop Technologies, Houston, TX, USA), and reverse-transcribed. RT-PCR amplification was performed in a Roche Lightcycler 480 II (Switzerland) using TaqMan assays. Relative expression of SREBP1, fatty acid synthase (FAS), carnitine palmitoyltransferase I (CPT1), ABCG5, and actin as housekeeping gene was calculated by $2^{-\Delta \Delta C T}$ method (Livak and Schmittgen 2001).

\section{Protein extraction and Western blotting}

Protein extraction and Western blotting were performed as previously reported (González-Granillo et al. 2012). Briefly, primary rat hepatocytes were homogenized in lysis protein RIPA buffer and complete protease inhibitor cocktail tablets (Roche Applied Science, Germany). Total protein $(30 \mu \mathrm{g})$ was loaded on $8 \%$ polyacrylamide gels, separated by SDS-PAGE, and transferred to polyvinylidene difluoride (PVDF) membrane. Blots were blocked with nonfat dry milk (Bio-Rad, Hercules, CA, USA) and incubated overnight at $4{ }^{\circ} \mathrm{C}$ with the following primary antibodies: anti-SREBP1, anti-FAS, anti-CPT1, antiHMGCR, anti-tubulin, and anti-actin (Santa Cruz Biotechnology, Santa Cruz, CA, USA). Then, blots were incubated with the secondary antibody and revealed in ChemiDoc $^{\mathrm{TM}}$ XRS + System with Image $\mathrm{Lab}^{\mathrm{TM}}$ Software (Bio-Rad, Hercules, CA, USA). The bands were analyzed using the ImageJ $1.42 \mathrm{p}$ digital imaging processing software (http://rsb.info.nih.gov/ij/March/27/2012).

Statistical analysis

Results were expressed as mean \pm standard error. Data were analyzed with Graphpad Prism 6.0 and MINITAB 16 software. The statistical analysis was performed by oneway ANOVA followed by Tukey's test to identify significant differences between groups. Differences between means were compared at a level of significance of $P<0.05$. Every experiment was performed in triplicate.

\section{Results}

Identification and quantification of phytosterols

It was possible to identify specific free and conjugated sterols (Table 1) by comparing the mass spectra with the compounds that have been previously identified in the Fabaceae family, according to the fragmentation pattern and molecular ions previously reported (Kaloustian et al. 2008; Leisso et al. 2013; Ongoka et al. 2008), as well as the coincidence in the retention time of the respective standards. Stigmasterol was only found in its free form, whereas campesterol was found as free, acylated steryl glycoside and steryl glycoside; sitosterol was found in free and acylated steryl glycoside forms. Finally, $\Delta^{5}$-avenasterol was found as free and steryl glycoside forms (Table 1).

The 44.2, 30.1, and $25.4 \%$ of the identified phytosterols were acylated steryl glycosides, free forms, and steryl glycosides, respectively (Table 2). The most abundant free phytosterol found in the extract before and after acid hydrolysis was sitosterol with a concentration of 29.4 and $51.2 \mathrm{mg} / 100 \mathrm{~g}$, respectively (Table 2), and the most abundant conjugated phytosterols found in black bean seed coats were $\beta$-sitoesteryl (6'-O-linoleoyl)- $\beta$-D-glucoside $(41.2 \pm 0.1 \mathrm{mg} / 100 \mathrm{~g})$ and campesteryl- $\beta$-D-glucoside $(32.9 \pm 1.2 \mathrm{mg} / 100 \mathrm{~g})$ (Table 2).

\section{Inhibition of in vitro cholesterol micellar solubility}

The inhibition of cholesterol micellar solubility due to phytosterols of black bean seed coats was significantly higher than the effect achieved by any of the two phytosterol standards used as control (Fig. 1). Particularly, sitosterol at a concentration of $3 \mathrm{mg} / \mathrm{mL}$ inhibited cholesterol micellar solubility by $3.39 \pm 0.46 \%$ when commercial standard was used and $14.24 \pm 1.55 \%$ when it was 
Table 1 Free phytosterols, steryl glycosides, and acylated steryl glycosides found in black bean seed coat based on accurate mass and comparison with literature

\begin{tabular}{|c|c|c|c|c|}
\hline Compound & $\begin{array}{l}\text { Molecular } \\
\text { mass }\end{array}$ & $m / z$ & Positive MS assignment & References \\
\hline \multicolumn{5}{|l|}{ Free sterols } \\
\hline Stigmasterol & 412 & 395.36 & {$\left[\mathrm{M}+\mathrm{H}-\mathrm{H}_{2} \mathrm{O}\right]^{+}$} & Ongoka et al. (2008), Rozenberg (2003) \\
\hline Campesterol & 400 & $\begin{array}{l}383.35 \\
411.35 \\
821.69\end{array}$ & $\begin{array}{l}{\left[\mathrm{M}+\mathrm{H}-\mathrm{H}_{2} \mathrm{O}\right]^{+}} \\
{[\mathrm{M}+\mathrm{H}-2 \mathrm{H}]^{+}} \\
{[\mathrm{M}+\mathrm{M}-\mathrm{H}]^{+}}\end{array}$ & $\begin{array}{l}\text { Rozenberg (2003) } \\
\text { Rozenberg (2003) }\end{array}$ \\
\hline$\beta$-Sitosterol & 414 & 397.37 & {$\left[\mathrm{M}+\mathrm{H}-\mathrm{H}_{2} \mathrm{O}\right]^{+}$} & Kishore et al. (2011), Rozenberg (2003) \\
\hline$\Delta^{5}$-Avenasterol & 412 & $\begin{array}{l}395.35 \\
413.26\end{array}$ & $\begin{array}{l}{\left[\mathrm{M}+\mathrm{H}-\mathrm{H}_{2} \mathrm{O}\right]^{+}} \\
{[\mathrm{M}+\mathrm{H}]^{+}}\end{array}$ & Rozenberg (2003) \\
\hline \multicolumn{5}{|l|}{ Steryl glycosides } \\
\hline$\Delta^{5}$-Avenasterol- $\beta$-D-glucoside & 574 & $\begin{array}{l}395.27 \\
413.26 \\
592.48\end{array}$ & $\begin{array}{l}\text { [Aglycone }-3 \mathrm{H}- \\
\left.\mathrm{H}_{2} \mathrm{O}\right]^{+} \\
{[\text {Aglycone }+\mathrm{H}]^{+}} \\
{\left[\mathrm{M}+\mathrm{H}_{2} \mathrm{O}\right]}\end{array}$ & Rozenberg (2003) \\
\hline Campesteryl- $\beta$-D-glucoside & 562 & $\begin{array}{l}383.35 \\
419.25 \\
579.28 \\
595.25\end{array}$ & $\begin{array}{l}{\left[\text { Aglycone }+\mathrm{H}-\mathrm{H}_{2} \mathrm{O}\right]^{+}} \\
{\left[\text {Aglycone }+\mathrm{H}_{2} \mathrm{O}+\mathrm{H}\right]^{+}} \\
{\left[\mathrm{M}+\mathrm{H}_{2} \mathrm{O}-\mathrm{H}\right]^{+}} \\
{\left[\mathrm{M}+\mathrm{H}_{2} \mathrm{O}+3 \mathrm{H}\right]^{+}}\end{array}$ & Dweck (2006), Rozenberg (2003) \\
\hline \multicolumn{5}{|l|}{ Acylated steryl glycosides } \\
\hline $\begin{array}{l}\text { Campesteryl }\left(6^{\prime}-O \text {-linoleoyl)- } \beta \text {-D- }\right. \\
\text { glucoside }\end{array}$ & 824 & $\begin{array}{l}383.36 \\
821.69\end{array}$ & $\begin{array}{l}{\left[\text { Aglycone }+\mathrm{H}-\mathrm{H}_{2} \mathrm{O}\right]^{+}} \\
{[\mathrm{M}+\mathrm{H}-4 \mathrm{H}]^{+}}\end{array}$ & $\begin{array}{l}\text { Leisso et al. (2013) } \\
\text { Rozenberg (2003) }\end{array}$ \\
\hline$\beta$-Sitoesteryl $\left(6^{\prime}\right.$ - $O$-linoleoyl $)-\beta$-D-glucoside & 838 & $\begin{array}{l}837.56 \\
397.37\end{array}$ & $\begin{array}{l}{[\mathrm{M}+\mathrm{H}-2 \mathrm{H}]^{+}} \\
{\left[\text {Aglycone }+\mathrm{H}-\mathrm{H}_{2} \mathrm{O}\right]^{+}}\end{array}$ & $\begin{array}{l}\text { Rozenberg (2003) } \\
\text { Rozenberg (2003) }\end{array}$ \\
\hline
\end{tabular}

Table 2 Concentrations of phytosterols in extracts of black bean $(\mathrm{mg} / 100 \mathrm{~g}$ of seed coats) before and after acid hydrolysis

\begin{tabular}{|c|c|c|c|c|c|c|}
\hline Extract & $\begin{array}{l}\text { Stigmasterol } \\
\mathrm{mg} / 100 \mathrm{~g} \text { seed coats }\end{array}$ & Campesterol & $\beta$-Sitosterol & $\Delta^{5}$-Avenasterol & Total & ASG/SG ratio \\
\hline \multicolumn{7}{|c|}{ Non-hyd ${ }^{c}$} \\
\hline Free & $3.21 \pm 0.13$ & $10.20 \pm 1.54$ & $29.42 \pm 0.51$ & $1.09 \pm 0.41$ & $43.92 \pm 2.50$ & \\
\hline ASG & n.d & $23.60 \pm 0.85$ & $41.23 \pm 0.11$ & n.d. & $64.83 \pm 1.01$ & 1.74 \\
\hline SG & n.d. & $32.91 \pm 1.21$ & n.d. & $4.41 \pm 0.08$ & $37.32 \pm 1.20$ & \\
\hline Total & $3.21 \pm 0.13$ & $66.71 \pm 1.99$ & $70.65 \pm 1.51$ & $5.50 \pm 0.51$ & $146.07 \pm 3.54$ & \\
\hline \multicolumn{7}{|l|}{ Hyd } \\
\hline Free & $9.02 \pm 1.12$ & $21.17 \pm 1.10$ & $51.21 \pm 1.18$ & $2.95 \pm 0.94$ & $84.35 \pm 1.62$ & \\
\hline
\end{tabular}

$A S G$ acylated steryl glycosides, $S G$ steryl glycosides, $H y d$ hydrolyzed extract, n.d. not detectable

${ }^{\text {a }}$ Mean \pm SE of at least three replicates, the conjugated forms are quantified as equivalent of the free forms

used along with the rest of the components in the phytosterol extract from black bean seed coats.

Relative expression and Western blotting

Phytosterols contained in black bean seed coat at a concentration of $76.1 \mu \mathrm{g} / \mathrm{L}$ were able to significantly reduce the expression of SREBP1 and FAS in cultured rat hepatocytes. Moreover, they suppressed the effect of the liver X receptor (LXR) inductor, T0901317, reducing the relative mRNA abundance and protein expression of two of the main proteins involved in liver lipogenesis (FAS and SREBP) to the levels presented in non-stimulated primary hepatocytes (Fig. 2). ABCG5 was also downregulated by the phytosterol-rich extract, before and after the induction of LXR (Fig. 3) at mRNA and protein levels.

Interestingly, it was observed that the phytosterol extract was able to upregulate the expression of CPT1 at mRNA 


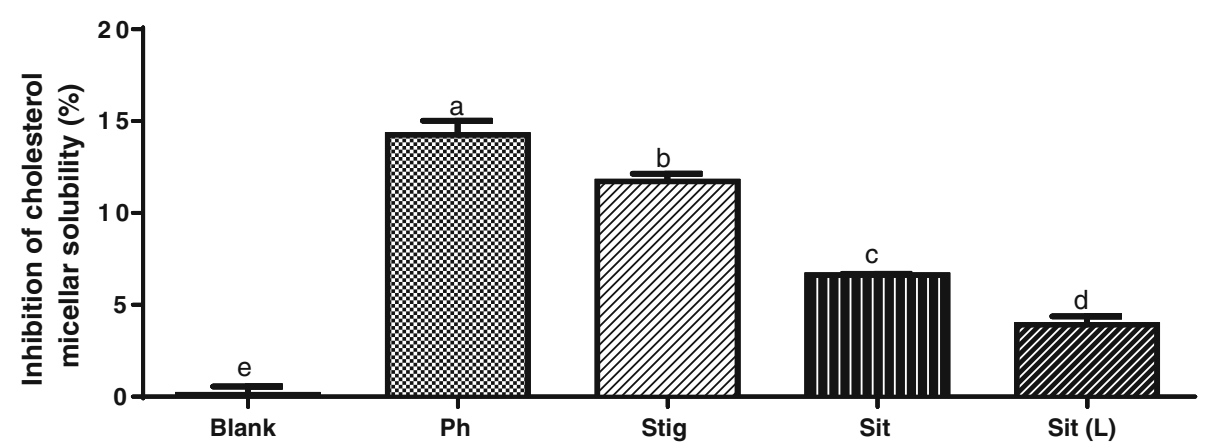

Fig. 1 Inhibition of cholesterol micellar solubility. The tested treatments were blank, the micellar mixture without any disruptor; $\mathrm{Ph}$, the extract rich in phytosterols (free and conjugated) of black bean seed coats $(5 \mathrm{mg} / \mathrm{mL})$; Stig, stigmasterol $(5 \mathrm{mg} / \mathrm{mL})$; Sit, sitosterol
$(5 \mathrm{mg} / \mathrm{mL})$; and Sit (L), sitosterol at a dose contained in phytosterols extract $(3 \mathrm{mg} / \mathrm{mL})$. Every experiment was performed in triplicate $(n=3)$. Data are presented in mean \pm SE. Bars with different letter indicate statistically significant difference, $P<0.05$
Fig. 2 Effect of phytosterols of black bean seed coats on the expression of lipogenic genes of the liver. It is presented at the left the relative gene expression, and at the right the protein expression of a FAS and b SREBP1 of primary hepatocytes treated; $\mathrm{CN}=$ no stimulus, $\mathrm{T}=$ the synthetic LXR agonist T0901317, $\mathrm{Ph}=$ phytosterols from black bean seed coat extract at $76.13 \mu \mathrm{g} / \mathrm{L}$,

$\mathrm{T}+\mathrm{Ph}=\mathrm{T} 0901317$ and the extract rich in phytosterols associated with black bean seed coat at the same dose $(76.13 \mu \mathrm{g} /$ L). Every experiment was performed in triplicate $(n=3)$. Data are presented in mean \pm SE. Bars with different letter indicate statistically significant difference, $P<0.05$

\section{a}

FAS

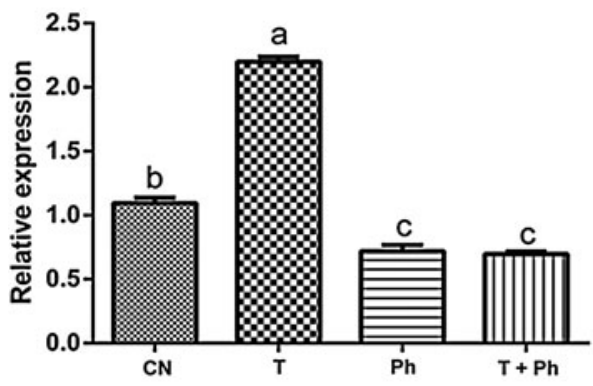

b

SREBP1

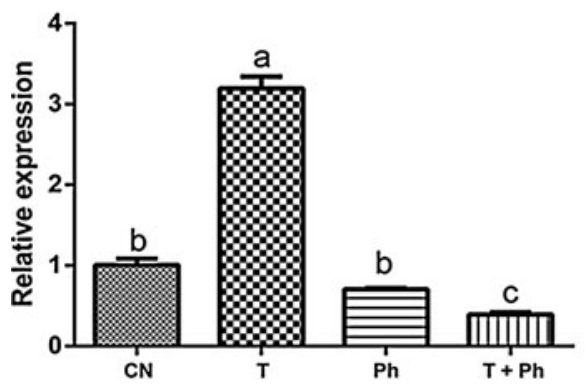

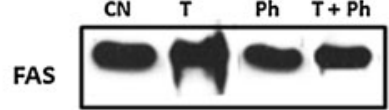

$\beta$-Actin
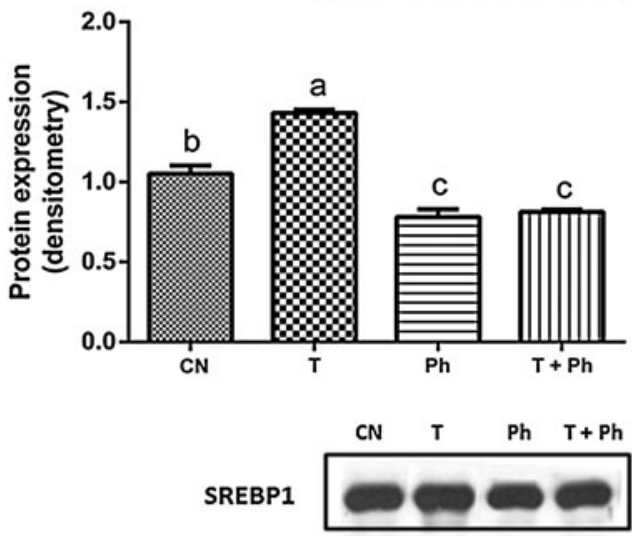

$\beta$-Actin

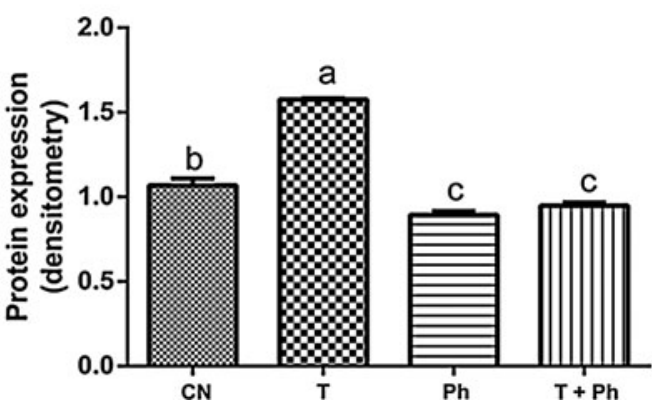

and protein level (Fig. 4). The LXR induction by T0901317 reduced the mRNA abundance and protein expression of the key enzyme of $\beta$-oxidation CPT1 (Fig. 4), but the addition of phytosterols extract to stimulate hepatocytes increased CPT1 expression to normal levels (Fig. 4).

\section{Discussion}

This research is the first to report the profile of phytosterols associated with bean seed coats. Sitosterol was the major phytosterol, and the concentration determined herein is similar to that reported for other related seeds of the 
a

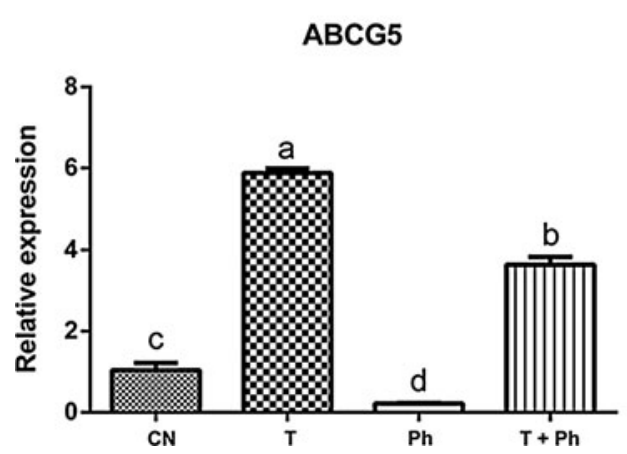

Fig. 3 Effect of phytosterols of black bean seed coats on the expression of ABCG5 (transport protein responsible for biliary excretion of sterols in the liver). It is presented the a relative expression and $\mathbf{b}$ protein expression of ABCG5 in primary hepatocytes treated with control or $\mathrm{CN}=$ no stimulus, $\mathrm{T}=$ the synthetic LXR agonist T0901317, $\mathrm{Ph}=$ extract rich in phytosterols associated

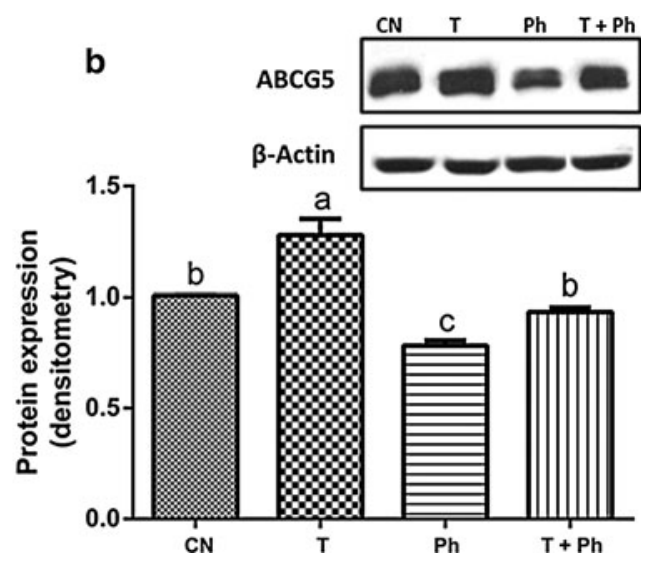

with black bean seed coat at a dose of $76.13 \mu \mathrm{g} / \mathrm{L}$. $\mathrm{T}+\mathrm{Ph}=\mathrm{T} 0901317$ and the extract rich in phytosterols associated with black bean seed coat at the same dose $(76.13 \mu \mathrm{g} / \mathrm{L})$. Every experiment was performed in triplicate $(n=3)$. Data are presented in mean \pm SE. Bars with different letter indicate statistically significant difference, $P<0.05$ a

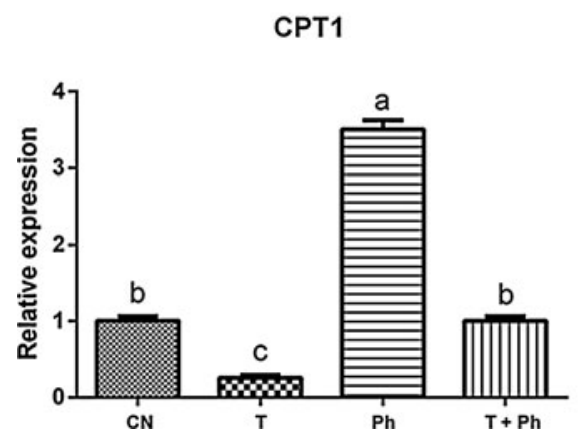

Fig. 4 Effect of phytosterols of black bean seed coats in the expression of CPT1 (rate-limiting enzyme for $\beta$-oxidation of longchain fatty acids in the liver). It is presented the a relative expression and $\mathbf{b}$ protein expression of CPT1, which mediates the transport of long-chain fatty acids across the mitochondrial membrane by binding them to carnitine for $\beta$-oxidation, in primary hepatocytes treated with $\mathrm{CN}=$ no stimulus, $\mathrm{T}=$ the synthetic LXR agonist $\mathrm{T} 0901317$,

Fabaceae family such as kidney and common beans that contained 86.5 and $27.2 \mathrm{mg} / 100 \mathrm{~g}$ of sitosterol, respectively (Iriti et al. 2009; Ryan et al. 2007). Sitosterol, campesterol, and stigmasterol contents found after hydrolysis were comparable to the concentrations previously reported in linseed, spelt, and rye (Ryan et al. 2007). As expected, from previous reports in common beans (Nyström et al. 2012), the amount of acylated steryl glycosides was higher than that of steryl glycosides (Table 2). Furthermore, the ASG/SG ratio obtained was 1.74 , which is similar to the ratio 1.79 previously reported for black bean (Nyström et al. 2012). This ratio is important in estimating the bioactivity of the phytosterols associated with seed b

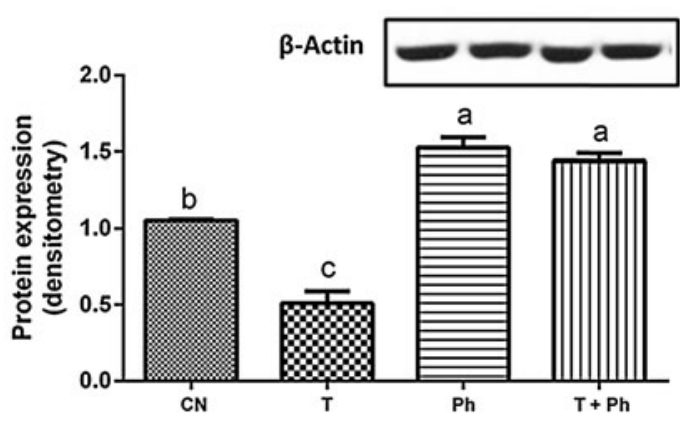

$\mathrm{Ph}=$ extract rich in phytosterols associated with black bean seed coat at a dose of $76.13 \mu \mathrm{g} / \mathrm{L} . \mathrm{T}+\mathrm{Ph}=\mathrm{T} 0901317$ and the extract rich in phytosterols associated with black bean seed coat at the same dose $(76.13 \mu \mathrm{g} / \mathrm{L})$. Every experiment was performed in triplicate $(n=3)$. Data are presented in mean \pm SE. Bars with different letter indicate statistically significant difference, $P<0.05$

coats. It has been reported that ASG are more bioactive than the GS in lowering cholesterol absorption in mice (Lin et al. 2011), and therefore, the phytosterol profile of black bean seed coats contains more bioactive conjugated sterols.

Results of the in vitro studies suggest that the enhancement of the inhibition of cholesterol micellar solubility was due to the synergistic effect of free and conjugated phytosterols contained in the extract. There is evidence that dietary phytosterols reduced serum and hepatic cholesterol levels by interfering with the intestinal absorption, through the inhibition of its micellar solubility (Carr et al. 2005; Trautwein and Duchateau 2003). Additionally, it has been demonstrated that ASG reduced 
cholesterol absorption by $45 \pm 6 \%$ in mice in contrast to the null effect of the free forms (Lin et al. 2011). Other compounds contained in black bean seed coats have been studied for their effect on the inhibition of cholesterol micellar solubility, such as saponins, which strongly inhibited cholesterol micellization with values higher than $50 \%$ (Chávez-Santoscoy et al. 2013).

The downregulatory effect on lipogenic genes (SREBP1 and FAS) of the phytosterol extract was consistent with previous reports that demonstrated that sitosterol and stigmasterol downregulated the expression of other relevant proteins involved in cholesterol biosynthesis, such as SREBP-2 and HMGCR (Liang et al. 2011). Moreover, it has been demonstrated hepatic downregulation of SREBP1 in C57BL/6 mice fed with a mixture of phytosterols in their free forms (Rideout et al. 2010). It is well established that the expression of the transcription factor SREBP-1, essential for the transcriptional control of lipogenic genes, is strongly upregulated by the transcription factor LXR. Particularly, the isoform LXR- $\alpha$ is the mainly responsible for upregulating the expression of SREBP-1 when stimulated with either natural oxysterols or synthetic LXR ligands such as T0901317. Interestingly, phytosterols were able to almost abolish the stimulating effect of T0901317 on SREBP1 and FAS expression to the levels observed in non-stimulated primary hepatocytes.

Furthermore, phytosterols of black bean seed coats decreased the relative expression of ABCG5, another target of the transcription factor LXR, in primary hepatocytes incubated with T0901317. Nonetheless, as expected, ABCG5 was overexpressed by the LXR inductor T0901317 (Fig. 3) (Calpe-Berdiel et al. 2008; Pawar et al. 2003), in primary hepatocytes non-incubated with phytosterols.

The downregulation of SREBP1, FAS, and ABCG5 by phytosterols of black bean seed coats in hepatocytes incubated with T0901317 suggests that the sterols inhibited the LXR activity. There is evidence that other bioactive compounds such as isoflavones have similar effects on LXR activity (González-Granillo et al. 2012). It has been suggested that these compounds could regulate the activity of the enzyme adenosine monophosphate kinase (AMPK), and this in turn could modulate the phosphorylation state of LXR modifying its biological activity (González-Granillo et al. 2012). However, more studies are needed to understand whether the phytosterols are able to alter the LXR phosphorylation state. Nonetheless, it is known that systemic LXR activation increases hepatic fatty acid synthesis and steatosis (De Smet et al. 2012), and therefore, phytosterols of black bean seed coats can potentially be used to reduce or prevent these abnormalities.
Interestingly, it was observed that the synthetic ligand T0901317 reduced the mRNA and protein expression of the key enzyme of $\beta$-oxidation CPT1. In contrast, phytosterols associated with black bean seed coats upregulated the expression of CPT1, promoting $\beta$-oxidation of longchain fatty acids. Moreover, they were able to suppress the downregulating effect of T0901317 over the expression of CPT1, causing the enzyme to be expressed at similar levels observed in non-stimulated primary hepatocytes (Fig. 4a). Remarkably, at the protein level, the expression of CPT1 of primary hepatocytes treated with T0901317 with phytosterols of black bean seed coat $(\mathrm{T}+\mathrm{Ph})$ was higher than that observed in non-stimulated primary hepatocytes (Fig. 4b).

In summary, our results suggest that phytosterols of black bean seed coats can potentially reduce cholesterol levels by inhibiting its absorption in the intestinal lumen through the inhibition of cholesterol micellar solubility. Furthermore, the downregulation of LXR target genes (SREBP1, FAS, and ABCG5) suggested that these phytosterols were able to suppress the activity of LXR, reducing the expression of lipogenic genes that are known to reduce hepatic lipogenesis. In addition, phytosterols of black bean seed coats upregulated the expression of CPT1, which promoted the $\beta$-oxidation of long-chain fatty acids. Further experiments are needed to determine the in vivo effects of these phytochemicals in humans.

Acknowledgments This research was supported by the Nutrigenomic Research Chair Funds from Tecnologico de Monterrey-Campus Monterrey and Consejo Nacional de Ciencia y Tecnología (CONACYT).

Conflict of interest None.

\section{References}

Berry MN, Friend DS (1969) High-yield preparation of isolated rat liver parenchymal cells: a biochemical and fine structural study. J Cell Biol 43:506-520

Calpe-Berdiel L, Rotllan N, Fiévet C, Roig R, Blanco-Vaca F et al (2008) Liver X receptor-mediated activation of reverse cholesterol transport from macrophages to feces in vivo requires ABCG5/G8. J Lipid Res 49:1904-1911

Carr T (2002) Plant sterols alter bile acid metabolism and reduce cholesterol absorption in hamsters fed a beef-based diet. Nutr Res 22:745-754

Carr TP, Weller CL, Schlegel VL, Cuppett SL, Guderian DM, Johnson DM (2005) Grain sorghum lipid extract reduces cholesterol absorption and plasma non-HDL cholesterol concentration in hamsters. J Nutr 135:2236-2240

Chávez-Santoscoy RA, Gutiérrez-Uribe JA, Serna-Saldívar SO (2013), Effect of flavonoids and saponins extracted from black bean (Phaseolus vulgaris L.) seed coats as cholesterol micelle disruptors. Plant Foods Hum Nutr 68(4):416-423 
De Smet E, Mensink RP, Plat J (2012) Effects of plant sterols and stanols on intestinal cholesterol metabolism: suggested mechanisms from past to present. Mol Nutr Food Res 56:1058-1072

Díaz-Batalla L, Widholm JM, Fahey JC Jr, Castaño-Tostado E, Paredes-López O (2006) Chemical components with health implications in wild and cultivated Mexican common bean seeds (Phaseolus vulgaris L.). J Agric Food Chem 54:2045-2052

Dweck AC (2006) Isoflavones, phytohormones and phytosterols. J Appl Cosmetol 33:17-32

Food and Drug Administration (2010) Food labeling; health claim; phytosterols and risk of coronary heart disease; proposed rule. Fed Reg 75(235):76526-76571

González-Granillo M, Steffensen KR, Granados KR, Torres N, Korach-André M et al (2012) Soy protein isoflavones differentially regulate liver $\mathrm{X}$ receptor isoforms to modulate lipid metabolism and cholesterol transport in the liver and intestine in mice. Diabetologia 22:2469-2478

Graf GA, Li WP, Gerard RD (2002) Coexpression of ATP-binding cassette proteins ABCG5 and ABCG8 permits their transport to the apical surface. J Clin Invest 110:659-669

Guderian DM, Rasmussen HE, Wray CA, Dussault PH, Carr TP (2007) Cholesterol-lowering properties of plant sterols esterified with beef tallow fatty acids in hamsters. Nutr Res 27:283-288

Horton J (2002) SREBPs: activators of the complete program of cholesterol and fatty acid synthesis in the liver. J Clin Invest 109:1125-1131

Iriti M, Di Maro A, Bernasconi S, Burlini N, Simonetti P et al (2009) Nutritional traits of bean (Phaseolus vulgaris) seeds from plants chronically exposed to ozone pollution. J Agric Food Chem 57:201-208

Jesch E, Carr T (2006) Sitosterol reduces micellar cholesterol solubility in model bile. Nutr Res 26:579-584

Kaloustian J, Alhanout K, Amiot-Carlin MJ, Lairon D, Portugal H et al (2008) Effect of water cooking on free phytosterol levels in beans and vegetables. Food Chem 107:1379-1386

Kishore K, Roy D, Pt G, College SCS (2011) Tephrosia purpurea Pers. (Fabaceae) - a common winter weed of Chhattisgarh, India - as a source of anticancer drug. Indian J Appl Pure Biol 26:53-55

Lee SD, Gershkovich P, Darlington JW, Wasan KM (2012) Inhibition of cholesterol absorption: targeting the intestine. Pharm Res 29:3235-3250

Leisso R, Buchanan DA, Lee J, Mattheis J, Rudell DR (2013) Cell wall, cell membrane, and volatile metabolism are altered by antioxidant treatment, temperature shifts, and peel necrosis during apple fruit storage. J Agric Food Chem 61:1373-1387

Liang YT, Wong WT, Guan L, Tian XY, Ma KY et al (2011) Effect of phytosterols and their oxidation products on lipoprotein profiles and vascular function in hamster fed a high cholesterol diet. Atherosclerosis 219:124-133
Lin X, Ma L, Racette SB, Anderson Spearie CL, Ostlund RE (2009) Phytosterol glycosides reduce cholesterol absorption in humans. Am J Physiol Gastrointest Liver Physiol 296:G931-G935

Lin X, Ma L, Moreau RA, Ostlund RE (2011) Glycosidic bond cleavage is not required for phytosteryl glycoside-induced reduction of cholesterol absorption in mice. Lipids 46:701-708

Livak KJ, Schmittgen TD (2001) Analysis of relative gene expression data using real-time quantitative PCR and the 2(-Delta Delta C(T)) method. Methods 25:402-408

Maitani Y, Nakamura K, Kawano K (2005) Application of sterylglucoside-containing particles for drug delivery. Curr Pharm Biotechnol 6:81-93

National Cholesterol Education Program (NCEP) (2001) Expert panel on detection evaluation and treatment of high blood cholesterol in adults. JAMA 285:2486-2497

Nyström L, Schär A, Lampi AM (2012) Steryl glycosides and acylated steryl glycosides in plant foods reflect unique sterol patterns. Eur J Lipid Sci Technol 114:656-669

Ongoka P, Banzouzi J, Poupat C (2008) Steroids isolated from Millettia versicolor Baker (Fabaceae). Afr J Biotechnol 7:1727-1730

Ostlund RE (2002) Phytosterols in human nutrition. Annu Rev Nutr $22: 533-549$

Ostlund RE (2004) Phytosterols and cholesterol metabolism. Curr Opin Lipidol 15:37-41

Pawar A, Botolin D, Mangelsdorf DJ, Jump DB (2003) The role of liver $\mathrm{X}$ receptor-alpha in the fatty acid regulation of hepatic gene expression. J Biol Chem 278:40736-40743

Rasmussen HE, Guderian DM, Wray CA, Dussault PH, Schlegel VLet al (2006) Reduction in cholesterol absorption is enhanced by stearateenriched plant sterol esters in hamsters. J Nutr 136:2722-2727

Rideout TC, Harding SV, Jones PJH (2010) Consumption of plant sterols reduces plasma and hepatic triglycerides and modulates the expression of lipid regulatory genes and de novo lipogenesis in C57BL/6J mice. Mol Nutr Food Res 54:S7-S13

Rozenberg R (2003) Phytosterol analysis and characterization in spelt (Triticum aestivum ssp. spelta L.) and wheat (T. aestivum L.) lipids by LC/APCI-MS. J Cereal Sci 38:189-197

Ryan E, Galvin K, O'Connor TP, Maguire AR, O'Brien NM (2007) Phytosterol, squalene, tocopherol content and fatty acid profile of selected seeds, grains, and legumes. Plant Foods Hum Nutr 62:85-91

Sato R (2010) Sterol metabolism and SREBP activation. Arch Biochem Biophys 501:177-181

Trautwein EA, Duchateau GS (2003) Proposed mechanisms of cholesterol-lowering action of plant sterols. Eur J Lipid Sci Technol 105:171-185

Zhong F, Liu J, Ma J, Shoemaker CF (2007) Preparation of hypocholesterol peptides from soy protein and their hypocholesterolemic effect in mice. Food Res Int 40:661-667 